\title{
Qualidade fisiológica de sementes de soja com mancha púrpura
}

\author{
Keilor Rosa Dorneles ${ }^{*}$, Anderson Eduardo Brunetto ${ }^{1}$, Leandro José Dallagnol ${ }^{1}$, Daniele Brandstetter \\ Rodrigues $^{1}$, Lilian Vanussa Madruga Tunes ${ }^{1}$
}

\begin{abstract}
RESUMO: O objetivo com essa pesquisa foi elucidar o efeito da severidade e da localização da mancha púrpura no tegumento de sementes de soja na qualidade fisiológica e no desenvolvimento inicial da plântula. Sementes da cultivar de soja M5947 IPRO foram separadas em quatro classes de severidade da mancha púrpura: classe 1 - sementes assintomáticas, classe 2 - pigmentação purpúrea na porcentagem de 0,1 a $10 \%$, classe $3-10$ a $50 \%$, e classe $4-50$ a $100 \%$. Os tratamentos foram organizados em delineamento inteiramente casualizado. A severidade da mancha purpura na semente não influenciou os valores de condutividade elétrica e a emergência da plântula em solo. Em relação ao teste de envelhecimento acelerado, não ocorreu variação significativa entre as diferentes classes de severidade da mancha purpura, exceto pelo maior comprimento da raiz e a menor porcentagem de sementes mortas na classe 3 comparada a classe 4. Por outro lado, maior porcentagem de plântulas anormais foi observada para sementes com o sintoma da doença associado ao hilo. Sementes com mancha púrpura, independente da severidade da mancha púrpura, não sofrem perdas na sua qualidade fisiológica. Porém, quando o sintoma da doença está associado ao hilo, há maior porcentagem de plântulas anormais no teste de emergência em solo.
\end{abstract}

Palavras-chave: Cercospora sp., Glycine max L., Germinação, Sanidade de sementes.

\section{Physiological quality of soybean seeds with purple spot}

\begin{abstract}
The purpose of this research was to elucidate the effect of the severity and location of the purple spot on the seed coat of soybean on the physiological quality and initial seedling development. Seeds of the soybean cultivar M5947 IPRO were separated into four classes of purple spot severity: class 1 - asymptomatic seeds, class 2 - purple pigmentation in the percentage of 0.1 to $10 \%$, class $3-10$ to $50 \%$, and class $4-50$ to $100 \%$. The treatments were organized in a completely randomized design. The severity of the purple spot on the seed did not influence the values of electrical conductivity and the emergence of the seedling in soil. Regarding the accelerated aging test, there was no significant variation between the different classes of severity of the purple spot, except for the greater length of the root and the lower percentage of dead seeds in class 3 compared to class 4 . On the other hand, a higher percentage of abnormal seedlings were observed for seeds with the disease symptom associated with hilum. In conclusion, seeds with a purple spot, regardless of the severity of the purple spot, do not suffer losses in their physiological quality. However, when the disease symptom is associated with hilum, there is a higher percentage of abnormal seedlings in the soil emergency test.

Keywords: Cercospora sp., Glycine max L., Germination, Seed health.
\end{abstract}

\section{INTRODUÇÃO}

A soja (Glycine max L. Merrill) é fonte de proteína e é utilizada como principal componente na fabricação de rações para os animais, além do papel de destaque na alimentação humana, sendo consumida tanto na forma de óleo, quanto de grãos e outros derivados, bem como para a produção de biodiesel (DESTRO et al., 2013; CONCEIÇÃO et al., 2014). A soja ocupa posição de destaque na agricultura brasileira, sendo uma das culturas com maior área cultivada. $\mathrm{Na}$ safra 2018/2019 ocupou aproximadamente 35,822 milhões de hectares rendendo uma produção de 114,84 milhões de toneladas (CONAB, 2019). Por meio da adequação das práticas de manejo e do melhoramento genético, a produtividade avançou de 1, $748 \mathrm{ha}^{-1} \mathrm{em} \mathrm{1976/77,}$ para $3,333 \mathrm{~kg} \mathrm{ha}^{-1}$ na safra de 2018/2019, sendo duplicada em quatro décadas (CONAB, 2019).

Dessa forma, um dos insumos mais importante da lavoura, envolvidos nessa caminhada rumo a altas produtividades é a semente de qualidade. Entre os atributos importantes da semente estão alta porcentagem germinação, vigor e sanidade, bem como garantias de purezas física e genética (HAMAWAKI et al., 2002). Esses atributos proporcionam rápido estabelecimento das plantas nos campos de produção, onde permite que se tenha uma lavoura mais uniforme e produtiva (WENDT et al., 2017).

Problemas sanitários, como ocorrência de patógenos associados a semente, comprometem a possibilidade de obtenção de ganhos maiores de produção por área com menor custo (COSTA et al., 2018). Dentre os patógenos que infectam a semente, o de maior prevalência é o fungo Cercospora kikuchii Matsu. e Tomoyasu, agente causal do crestamento foliar e da mancha púrpura em semente, que ocorre em todas as regiões produtoras de soja, principalmente naquelas mais quentes e chuvosas, e é uma das doenças que compõem o 
"complexo de doenças foliares de final de ciclo" da cultura (GONZÁLEZ et al., 2008).

$\mathrm{O}$ fungo C. kikuchii ataca todas as partes da planta e pode ser responsável por severas reduções do rendimento e da qualidade da semente. Nas folhas, os sintomas são pontuações escuras, castanhoavermelhadas, as quais coalescem e formam grandes manchas escuras que resultam em severo crestamento e desfolha prematura (ALMEIDA et al., 2001). Nas vagens surgem pontuações vermelhas que evoluem para manchas castanho-avermelhadas. Através da vagem, o fungo atinge a semente e causa a mancha púrpura no tegumento, daí a denominação da doença como mancha púrpura, no entanto, nem toda a semente infectada apresenta a cor característica no tegumento, podendo estar de maneira assintomática (GALLI et al., 2005). A descoloração do tegumento acontece devido a presença da toxina cercosporina. Essa toxina, além de desencadear danos na membrana celular, causa a oxidação de lipídios, proteínas e ácidos nucleicos, comprometendo a viabilidade da semente (DAUB; CHUNG, 2007). Assim, as sementes de soja colonizadas pela C. kikuchii apresentam a sua qualidade comprometida, tanto pela depreciação visual pela pigmentação arroxeada no tegumento, quanto fisiológica, pela redução na germinação e geração de plântulas menos vigorosas, além do agravante de atuar como fonte de inóculo para área de produção indenes da doença (OLIVEIRA et al., 1993; PEREIRA et al., 2017).

Por outro lado, estudos apontaram não haver nenhum efeito negativo do fungo sobre a qualidade da semente, bem como há baixa taxa de transmissibilidade do fungo semente-planta-semente (OLIVEIRA et al., 1993; HENNING, 2004). À vista disso, mesmo havendo opiniões contrarias por demais pesquisadores que apontavam danos na qualidade da semente e perdas na produção, o Ministério da Agricultura, Pecuária e Abastecimento (MAPA) através da instrução normativa $\mathrm{n}^{\circ} 11$, de 15 de maio de 2007, que define o regulamento técnico da soja, considera que a presença de mancha púrpura em sementes de soja não é considerada defeito, removendo o padrão de tolerância, que era de até $10 \%$ de ocorrência de mancha púrpura no lote de sementes (CGQV, 2018).

Entretanto, nas últimas safras foi verificada ocorrência de maneira epidêmica da mancha púrpura, principalmente em cultivares ciclo precoce. A doença tem sido observada de forma mais agressiva sobre a semente, pigmentando a em sua totalidade e com coloração mais pronunciada e intensa, bem como causando rachaduras no tegumento a partir do hilo. Esse fato, tem gerado transtorno aos produtores de sementes, principalmente pela possibilidade de haver o descarte dos lotes produzidos, devido ao baixo atributo físico e também sanitário.
Diante do exposto, objetivou-se com essa pesquisa, elucidar o efeito da severidade e da localização da mancha púrpura no tegumento de sementes de soja na qualidade fisiológica e no desenvolvimento inicial de plântulas.

\section{MATERIAIS E MÉTODOS}

A cultivar de soja M5947 IPRO (Monsoy®) foi utilizada no estudo. As sementes foram obtidas de uma lavoura destinada à produção de sementes de um produtor da região central do estado do Rio Grande do Sul. Os tratos culturais da lavoura foram conforme as recomendações técnicas para a cultura (CARAFFA et al., 2018).

As sementes foram separadas em quatro classes de severidade da mancha púrpura, como segue: Classe 1 - sementes assintomáticas (controle); Classe 2 sementes apresentando pigmentação purpúrea de 0,1 a $10 \%$ da superfície; Classe 3 - de 10 a $50 \%$ da superfície; e Classe 4 - sementes de 50 a $100 \%$ de pigmentação da superfície. Os tratamentos foram organizados em delineamento inteiramente casualizado. Para a quantificação das variáveis que representam a qualidade fisiológica da semente (germinação, emergência em solo, condutividade elétrica e envelhecimento acelerado) foi considerado o esquema unifatorial, consistindo de uma cultivar de soja em quatro classes de severidade da mancha púrpura (classe 1; 2; 3 e 4), com quatro repetições (cada repetição constituída por 25 sementes).

Para avaliar o efeito da localização dos sintomas da mancha púrpura em relação ao hilo foi considerado o esquema fatorial consistindo de sementes de soja em quatro classes de severidade da mancha púrpura (classe $1 ; 2 ; 3$ e 4 ) e posição ao hilo (sintomas próximos ao hilo ou oposto ao hilo), com cinco repetições (cada repetição constituída por 25 sementes).

Germinação $(\mathrm{G})$ : realizado com quatro repetições de 25 sementes por tratamento, em rolo de papel Germitest, umedecido com quantidade de água equivalente a 2,5 vezes o peso do substrato, em germinador a $25^{\circ} \mathrm{C}$. As contagens foram realizadas aos cinco e oito dias após a semeadura, segundo os critérios estabelecidos pelas RAS e os resultados expressos em porcentagem (BRASIL, 2009).

Emergência de plântulas em solo: a semeadura foi realizada em cinco bandejas plásticas com capacidade 20 litros, de $0,60 \times 0,38 \times 0,15 \mathrm{~m}$, contendo aproximadamente $19 \mathrm{~kg}$ de solo natural peneirado. As características físico-químicas do solo utilizado no estudo foram as seguintes: $54 \mathrm{~g}$. $\mathrm{kg}^{-1}$ silte; $251 \mathrm{~g}$. kg argila; classe textural médio argiloso; $\mathrm{pH}$ em água 5,$8 ; 12 \mathrm{mg} . \mathrm{dm}^{-3} \mathrm{P} ; 6 \mathrm{mg}$. dm ${ }^{-3} \mathrm{~S} ; 5,8 \mathrm{mg} . \mathrm{dm}^{-3} \mathrm{~K} ; 3,1$ cmolc. $\mathrm{dm}^{-3} \mathrm{Ca} ; 1,7$ cmolc. $\mathrm{dm}^{-3} \mathrm{Mg}, 0,6$ cmolc. $\mathrm{dm}^{-3}$ $\mathrm{Al} ; 4,4$ cmolc. $\mathrm{dm}^{-3} \mathrm{H}+\mathrm{Al} ; 53 \%$ Saturação por Bases; 1,99\% MO; Índice SMP 6. 
Em cada bandeja foram semeadas quatro linhas de 25 sementes, sendo cada linha correspondente a um tratamento. As avaliações iniciaram a partir da emergência da primeira plântula até a estabilização aos 15 dias após a semeadura. No momento da última contagem, determinou-se a porcentagem de emergência (E) e o índice de velocidade de emergência (IVE). O IVE foi determinado pela contagem do número de plântulas emergidas a cada dia, a partir da semeadura até o ultimo dia de avaliação, sendo calculado pela fórmula: IVE $=\mathrm{N} 1+$ $\mathrm{N} 2+\mathrm{Nn} / \mathrm{Dn}$. Sendo: IVE = índice de velocidade de emergência, $\mathrm{N}=$ número de plântulas normais verificadas no dia da contagem e $\mathrm{D}=$ número de dias após a semeadura em que foi realizada a contagem (NAKAGAWA, 1994).

Condutividade elétrica (CE): realizada com quatro repetições de 25 sementes para cada tratamento, previamente escolhidas para remoção daquelas com tegumento danificado. As sementes foram pesadas com balança de precisão de $0,01 \mathrm{~g}$, colocadas em tubos Falcon contendo $30 \mathrm{~mL}$ de água deionizada e mantidas em câmara BOD à temperatura de $25^{\circ} \mathrm{C}$. Após oito horas de embebição foi realizada a leitura da condutividade elétrica, em condutivímetro (Tecnopon mCA-150 - MS Tecnopon Instrumentação Científica), sendo os resultados expressos em $\mu \mathrm{S} \mathrm{cm}^{-1} \mathrm{~g}^{-1}$ (KRZYZANOWSKI et al., 1991).

Envelhecimento acelerado (EA): as sementes foram colocadas em caixas plásticas transparentes com tampa (Gerbox) contendo $40 \mathrm{~mL}$ de água destilada. $\mathrm{O}$ material foi acondicionado a $42^{\circ} \mathrm{C}$ durante 48 horas (PEREIRA et al., 2018). Após esse período, as sementes foram submetidas ao teste de germinação. Avaliando a primeira contagem (PCG), porcentagem de germinação (PG), plântulas anormais (PA) e sementes mortas (SM) e também, no momento da primeira contagem, se realizou as medições do comprimento de parte aérea (CPA) e de raiz (CR) conforme a metodologia descrita por Brasil (2009) e Oliveira et al. (2009).
As sementes sintomáticas da mancha púrpura da classe 2,3 e 4, foram separadas em relação à posição do sintoma purpúreo ao hilo [associado ao hilo $(\mathrm{H}) \mathrm{ou}$ não $(\mathrm{NH})$ ], sendo posteriormente realizado o teste de emergência em solo. A semeadura foi realizada em cinco bandejas plásticas com capacidade 40 litros, de $1,20 \times 0,76 \times 0,30 \mathrm{~m}$, contendo aproximadamente 38 $\mathrm{kg}$ de solo natural peneirado.

Em cada bandeja foram semeadas oito linhas com 25 sementes, sendo cada linha correspondente a um tratamento. As avaliações foram realizadas após a estabilização da emergência das plântulas aos 15 dias após a semeadura. Na avaliação foi determinada a porcentagem de plântulas normais e anormais emergidas e a porcentagem total de plântulas emergidas, pela soma das plântulas normais e anormais, ademais foi quantificado a massa seca da parte aérea (MAS), a partir de 10 plântulas por repetição, quais foram coletadas aleatoriamente e acondicionadas em envelopes de papel pardo e submetidas à secagem em estufa com ventilação forçada, sob temperatura de $70{ }^{\circ} \mathrm{C}$ (72 horas), sendo os resultados expressos em mg plântula-1.

Para evidenciar a normalidade dos dados foi aplicado o teste de Shapiro Wilk, para todas as variáveis realizadas nos experimentos. Os dados foram submetidos à análise de variância (ANOVA) e as médias dos tratamentos comparadas pelo teste de Tukey $(\mathrm{p} \leq 0,05)$ no software $\mathrm{SAS}{ }^{\circledR}$ (SAS Institute, 1989, Cary, NC).

\section{RESULTADOS E DISCUSSÃO}

A semente de soja é um dos principais insumos para implantação da lavoura, merecendo atenção quanto à qualidade fisiológica e sanitária. Neste estudo, a porcentagem de pigmentação da superfície da semente com o sintoma da mancha purpura não afetou a germinação, condutividade elétrica e a emergência de plântulas em solo (Tabela 1).

Em relação ao teste de envelhecimento acelerado,

Tabela 1. Germinação, condutividade elétrica (CE), porcentagem de emergência (E) e índice de velocidade emergência (IVE) de plântulas de soja, oriundas de sementes da cultivar M5947 IPRO, com diferentes classes de severidade da mancha púrpura.

\begin{tabular}{ccccc}
$\begin{array}{c}\text { Graus de severidade da } \\
\text { mancha púrpura }\end{array}$ & $\begin{array}{c}\text { Germinação } \\
\%\end{array}$ & $\begin{array}{c}\mathrm{CE} \\
\mu \mathrm{S} \mathrm{cm}^{-1} \mathrm{~g}^{-1}\end{array}$ & $\%$ & IVE \\
\hline Classe 1 & $88^{\mathrm{ns}}$ & $97^{\mathrm{ns}}$ & $96^{\mathrm{ns}}$ & $14^{\mathrm{ns}}$ \\
Classe 2 & 86 & 136 & 94 & 13 \\
Classe 3 & 90 & 99 & 100 & 14 \\
Classe 4 & 86 & 101 & 94 & 14 \\
\hline CV\% & 10 & 22 & 6 & 4
\end{tabular}

Tratamentos: Classe 1 (sementes assintomáticas), classe 2 (pigmentação purpúrea d e 0,1 a $10 \%$ da superfície), classe 3 (de 10 a $50 \%$ da superfície) e classe 4 (de 50 a 100\% de pigmentação da superfície). Ns= Médias não diferem estatisticamente entre si pelo teste de Tukey $(p \leq 0,05)$.

não ocorreu variação significativa entre as diferentes classes de severidade da mancha purpura, exceto pelo maior comprimento da raiz e a menor porcentagem de sementes mortas na classe 3 comparada a classe 4 . (Tabela 2).
Segundo Costa et al. (2003) sementes de soja que apresentam danos na região do eixo embrionário, na maioria das vezes, resultam em plântulas anormais (redução da parte aérea ou raiz) ou sementes mortas. Neste estudo também foi verificado que nas sementes 
de soja com o sintoma da mancha púrpura associado ao hilo ocorreu redução de $14 \%$ e $9 \%$ no peso de matéria seca da parte aérea e na porcentagem de plântulas normais, e aumento de $50 \%$ na porcentagem de plântulas anormais, quando comparado as sementes com sintomas ao oposto ao hilo (Figura 1).

Tabela 2. Primeira contagem de germinação (PCG-EA), comprimento de parte aérea (CPA-EA) e raiz (CR-EA) e porcentagem de germinação (G-EA) e de plântulas anormais (PA-EA) e sementes mortas (SM-EA) após o envelhecimento acelerado (EA) sementes da cultivar M5947 IPRO, com diferentes classes de severidade da mancha púrpura.

\begin{tabular}{ccccccc}
\hline \multirow{2}{*}{ Graus de severidade da mancha púrpura } & PCG-EA & CPA-EA & CR-EA & G-EA & PA-EA & SM-EA \\
& $\%$ & $----------c m---------$ & $------------\%---------------$ \\
\hline Classe 1 & $36^{\text {ns }}$ & $5,0^{\text {ns }}$ & $6,63 \mathrm{ab}$ & $43^{\text {ns }}$ & $344^{\text {ns }}$ & $15 \mathrm{ab}$ \\
Classe 2 & 31 & 4,0 & $6,58 \mathrm{ab}$ & 39 & 42 & $15 \mathrm{ab}$ \\
Classe 3 & 33 & 5,0 & $7,56 \mathrm{a}$ & 59 & 27 & $14 \mathrm{~b}$ \\
Classe 4 & 24 & 5,0 & $4,66 \mathrm{~b}$ & 41 & 30 & $30 \mathrm{a}$ \\
\hline CV\% & 27,33 & 15,20 & 22,85 & 24,75 & 28,63 & 31,37 \\
\hline
\end{tabular}

Tratamentos: Classe 1 (sementes assintomáticas), classe 2 (pigmentação purpúrea de 0,1 a $10 \%$ da superfície), classe 3 (de 10 a $50 \%$ da superfície) e classe 4 (de 50 a $100 \%$ de pigmentação da superfície). Médias seguidas pela mesma letra não diferem entre si pelo teste de Tukey $(\mathrm{p} \leq 0,05)$. Ns= Médias não diferem estatisticamente entre si pelo teste de Tukey $(\mathrm{p} \leq 0,05)$.
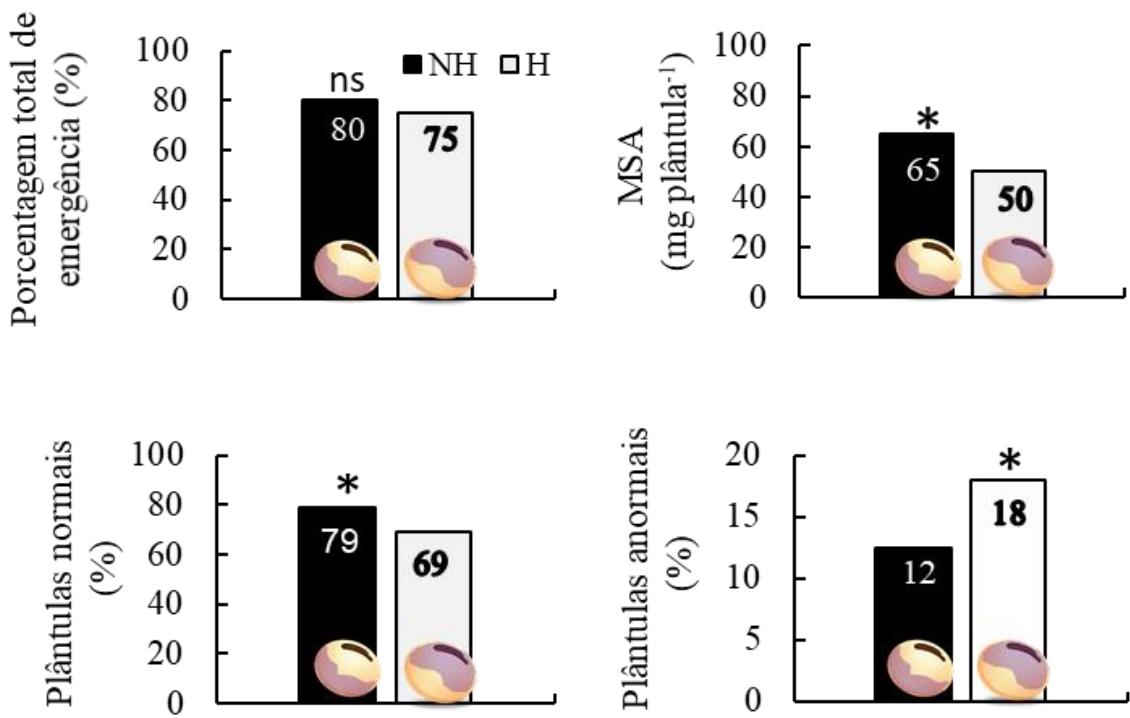

Figura 1 - Porcentagem total de emergência, plântula normais, plântulas anormais e massa seca da parte aérea (MSA) em relação a posição da mancha púrpura associado $(\mathrm{H})$ ou não associado ao hilo $(\mathrm{NH})$. ns = médias não são diferentes pelo teste- $t(p \leq 0,05)$. $*$ = médias são diferentes do teste- $t(p \leq 0,05)$.

Há estudos que apontam correlação positiva e negativa entre a severidade de $C$. kikuchii e a porcentagem de germinação e vigor das sementes de soja (HAMAWAKI et al., 2002; GALLI et al., 2005). Por exemplo, sementes da cultivar BRS MA Juçara com C. kikuchii apresentaram redução de $40 \%$ na germinação, em relação a sementes sadias. Além da redução do potencial de germinação, também é relatado, o aumento de sementes mortas e plântulas anormais (BRINGEL et al., 2001). Segundo Pereira et al. (2017), ao selecionaram sementes de soja com graus de severidade da mancha púrpura, de 1 a $25 \%$ e 25 a $50 \%$, observaram que em ambos os grupos apresentaram maiores porcentagens de plântulas anormais em relação as sementes sadias. Porém, Henning (2004) constatou que sementes de soja das cultivares Paraná, Davis e Bossier, com 0, 5, 10, 20 e $40 \%$ de mancha púrpura não diferiram entre si com relação à germinação, emergência em campo e rendimento de grãos. Câmara et al. (2019) também relataram que sementes de soja da cultivar RK7813 com até $100 \%$ de mancha púrpura não afetaram a germinação ou a emergência da plântula. A divergência entre os resultados das pesquisas supramencionadas, pode estar relacionado não apenas com a variação no nível de resistência entre os genótipos utilizados, mas também com relação ao patógeno, ao seu grau de colonização no tecido da semente e variabilidade genética. Um levantamento de populações de C. kikuchii, isolada da soja em diferentes regiões da Argentina (GONZÁLEZ et al., 2008) e do Brasil (ALMEIDA et al., 2005), demonstrou haver variabilidade entre os isolados em relação a sua capacidade de produzir a toxina cercosporina.

A cercosporina é uma toxina produzida pelo patógeno, que se pressupõem estar envolvida na descoloração do tegumento da semente, resultando na pigmentação característica da doença. A toxicidade é devido a sua reação com a luz, produzindo o radical hidroxila que causa peroxidação da membrana lipídica, comprometendo a integridade celular, que 
por sua vez, induz o vazamento de conteúdo citoplasmático e causa a morte celular (DAUB; CHUNG, 2007). O teste de condutividade elétrica que sinaliza a integridade do sistema de membrana (TUNES et al., 2008) não demonstrou diferença entre as sementes sadias e as com mancha púrpura. Dessa forma, pressupõe-se que a coloração da semente, não está estritamente correlacionada à maior colonização pelo patógeno ou maior presença dele no tecido. Assim, é passível de explicação a baixa taxa de transmissão do patógeno, encontrada em estudos, mesmo utilizando a semente com os sinais da doença (OLIVEIRA et al., 1993; GALLI et al., 2005).

Ademais, a analise filogenética de 70 espécies de Cercospora em soja indicou que há mais uma espécie que causa a mancha púrpura da semente ou crestamento foliar na soja, sendo identificado pelo menos duas espécies na Argentina, três no Brasil e cinco nas Américas (GUILLIN et al., 2017). Tal fato explica tanto a dificuldade em se obter genótipos resistentes à mancha púrpura quanto o porquê da grande variabilidade da eficácia das práticas de manejo e dos testes de danos, nas diferentes regiões onde é praticado.

\section{CONCLUSÕES}

As sementes de soja com mancha púrpura, analisadas nesse estudo não sofreram redução na sua emergência em solo, independente da severidade da doença. Porém, a localização do sintoma no tegumento da semente afeta a porcentagem de plântulas normais de soja. Assim, novos estudos devem ser realizados, visando identificar a correlação entre a severidade dos sintomas e a concentração do patógeno na semente bem como a identificação da espécie do patógeno para melhor auxiliar no controle de qualidade de forma geral.

\section{AGRADECIMENTOS}

K. R. Dorneles recebeu uma bolsa de estudo da Coordenação de Aperfeiçoamento de Pessoal de Nível Superior - Brasil - CAPES (Código de Financiamento 001). L. J. Dallagnol agradece ao Conselho Nacional de Desenvolvimento Científico $\mathrm{CNPq}$ - pela bolsa em pesquisa (Processo 308149/2018-1).

\section{REFERÊNCIAS}

ALMEIDA, A. M. R., ARTORI, F., CALVO, E. S., MARIN, S. R. R., FUKUJI, T. S. Diferenciação morfo-biomolecular de isolados de Cercospora kikuchii obtidos de sementes de soja no Brasil. Fitopatologia Brasileira, Brasília, v.26, p. 328, 2001.

ALMEIDA, Á. M. R., PIUGA, F. F., MARIN, S. R. R., BINNECK, E., SARTORI, F., COSTAMILAN, L. M., TEIXEIRA, M. R. O., LOPES, M. Pathogenicity, molecular characterization, and cercosporin content of
Brazilian isolates of Cercospora kikuchii. Fitopatologia Brasileira, Brasília, v.30, n. 6, p. 594-602, 2005.

BRASIL, Ministério da Agricultura e Reforma Agrária. Regras para análise de sementes. Brasília, DF: MAPA/ACS, 2009. 399 p.

BRINGEL, J. M. M. MORAES, M. H. D., MENTEN, J. O. M., BEDENDO, I. P. Qualidade sanitária e fisiológica de sementes de soja produzidas na Região de Balsa, Maranhão. Summa Phytopathologica, Jaboticabal, v.27, n. 4, p. 438-441, 2001.

CÂMARA, F. M. M., MONTEIRO, F. F., NADALETI, D. H. S., MOREIRA, R. A., AZEVEDO, H. P. A., BRUZI, A. T. Emergência de sementes de soja com diferentes porcentagens de infestação de mancha púrpura. Agropecuária Científica no Semiárido, Patos, v.15, n. 1, p. 18-22, 2019.

CARAFFA, M., PIRES, J. L. F., RUGERI, A. P., RIFFEL, C. T., HARTER, L. S. H., DANIELOWSKI, R., PIZZANI, $R$. Indicações técnicas para a cultura da soja no Rio Grande do Sul e Santa Catarina, safras 2018/2019 e 2019/2020. Três de Maio, RS, 2018, 105 pg.

CGQV-coordenação geral de qualidade vegetal. Padrão de Identidade e Qualidade da Soja, 2005. Disponível em: http://www.puntofocal.gov.ar/ doc/piq_soja.pdf. Acesso em: 06 abril. 2019.

CONAB- Companhia Nacional de Abastecimento. Acompanhamento da safra brasileira. Brasília, v. 6, n.9. 2019.

CONCEIÇÃO, G. M., BARBIERI, A. P. P., LÚCIO, A. D., MARTINI, T. N., MERTZ, L. M., MATTIONI, N. M., LORENTZ, L. H. Desempenho de plântulas e produtividade de soja submetida a diferentes tratamentos químicos nas sementes. Bioscience Journal, Uberlância, v. 30, n. 6, p. 1711-1720, 2014.

COSTA, E. M., NUNES, B. M., VENTURA, M. V. A., ARANTES, B. H. T., MENDES, G. R. Efeito fisiológico de inseticidas e fungicida sobre a germinação e vigor de sementes de soja (Glycine max L.) Científic@ Multidisciplinary Journal, Goianésia, v. 5, p. 77-84, 2018.

COSTA, N. P., MESQUiTA, C. M., MAURINA, A. C., FRANÇA NETO, J. B., KRZYZANOWSKI, F. C., HENNING, A. A. Qualidade fisiológica, física e sanitária de sementes de soja produzidas no Brasil. Revista Brasileira de Sementes, Pelotas, v. 25, n. 1, p. 128-132, 2003.

DAUB, M. E., CHUNG, K. R. Cercosporin: A Phytoactivated toxin in plant disease. Online. APSnet. 2007.http://www.apsnet.org/publications/apsnetfeatures/p ages/cercosporin.aspx. Acesso em: 10 junh. 2019.

DESTRO, D., FARIA, A. P., DESTRO, T. M., FARIA, R. T., GONÇALVES, L. S. A., LIMA, W. F. Food type 
soybean cooking time: a review. Crop Breeding and Applied Biotechnology, Viçosa, v. 13, n. 3, p. 194-199, 2013.

GALLI, J. A., PANIZZI, R. C., FESSEL, S. A., SIMONI, F., ITO, M. F. Effect of Colletotrichum dematium var. truncata and Cercospora Kikuchii on soybean seed germination. Revista Brasileira de Sementes, Pelotas, v.27, n. 2, p. 182-187, 2005.

GONZÁLEZ, A. M. TURINO, L., LATORRE, R. M. G., LURÁ, M. C. Cercospora kikuchii aislada en la província de Santa Fé (Argentina): variabilidad genética y producción de cercosporina in vitro. Revista Iberoamericana de Micología, Barcelona, v. 25, p. 237241, 2008.

GUILlin, E. A., OLIVEIRA, L. O., GRIJALBA, P. E., GOTTLIEB, A. M. Genetic entanglement between Cercospora species associating soybean purple seed stain. Mycological Progress, v. 16, p. 593-603, 2017.

HAMAWAKI, O.T., JULIATTI, F. C., GOMES, G. M., RODRIGUES, F. A., SANTOS, V. L. M. Avaliação da qualidade fisiológica e sanitária de sementes de genótipos de soja do ciclo precoce/médio em Uberlândia, Minas Gerais. Fitopatologia Brasileira, Brasília, v. 27, n. 2, p. 201-205, 2002.

HENNING, A. A. Patologia e tratamento de sementes: noções gerais. (EMBRAPA, documento. 235), 2004.

KRZYZANOWSKI, F. C., FRANCA-NETO, J. B., HENNING, A. A. Relato dos testes de vigor disponíveis para grandes culturas. Informativo Abrates, v. 1, 1991. $50 \mathrm{pg}$.
NAKAGAWA, J. Testes de vigor baseados na avaliação das plântulas. In: VIEIRA, R. D., CARVALHO, N. M. (Coord.). Testes de vigor em sementes. Fundação de Apoio a Pesquisa, Ensino e Extensão, Jaboticabal, SP, 1994. p.49-85.

OLIVEIRA, A. C. S., MARTINS, G. N., SilVA, R. F., VIEIRA, H. D. Testes de vigor em sementes baseados no desempenho de plântulas. Revista Científica Internacional. São Camilo, v.1, n. 4, p. 1-21, 2009.

OLIVEIRA, J. A., MACHADO, J. C., VIEIRA, M. G. G. C., BRANDÃO JÚNIOR, D. S. Transmissibilidade e danos causados por Cercospora kikuchii em sementes de soja. Revista Brasileira de Sementes, Brasília, v.15, n.1, p. $97-100,1993$.

PEREIRA, C. E.; PEREIRA, M. C. Sementes de soja infectadas por Cercospora kikuchii, sob déficit hídrico. Científica, Jaboticabal, v.45, n. 3, p. 295-299, 2017.

TUNES, L. M., BARROS, A. C. S. A., BADINELLI, P. G., OLIVO, F. Testes de vigor em função de diferentes épocas de colheita de sementes de cevada (Hordeum vulgare L.). Revista Brasileira de Ciências Agrárias, Recife, v.3, n. 4, p. 321- 326, 2008.

WENDT, L., MALAVASI, M. M., DRANSKI, J. A. L., MALAVASI, U. C., GOMES JUNIOR, F. G. Relationship between vigor tests with field emergency of soybean seed. Revista Brasileira de Ciências Agrarias, Recife, v. 12, p.166-171, 2017. 